\title{
Optical microscopy analysis of briquette binders
}

\author{
Yue Wang $\cdot$ Xiangfei Bai
}

Received: 10 March 2014/Revised: 1 December 2014/Accepted: 2 December 2014/Published online: 10 March 2015

(C) The Author(s) 2015. This article is published with open access at Springerlink.com

\begin{abstract}
Environmental requirements and demands from the coal industry have resulted in a boom in briquetting technology in China. In this work, a low-volatility bituminous coal from the Changcun mine and bentonite binders are used for briquetting. The compressive strength, impact strength, and thermal stability of briquettes made using different binder concentration are determined. The morphology and distribution of binders in briquettes are studied by optical microscopy and digital image-processing technologies. The concept of roundness is introduced to indicate the pressure to which the binders are subjected during briquetting. The influences of binder morphology on briquette strength are discussed. The binders are mainly in aggregated and dispersed forms, present in similar proportions in the briquettes. Aggregated binders with large differences in size are not well-distributed. Binder roundness values are concentrated between 1.5 and 4.0, which indicates that most aggregated binders are compressed and conform well to the surfaces of coal particles. A few binders had roundness value approximating 1 or above 4 , which indicated that these were under little pressure or overloaded, respectively. The relationships between briquette strength and binder morphology show that aggregated binders are detrimental to mechanical strength while dispersed binders benefit briquetting.
\end{abstract}

Keywords Briquettes $\cdot$ Binder $\cdot$ Optical analysis $\cdot$ Morphological characteristics

\section{Introduction}

In 2013, 3.7 billion tons of coal sample were mined and 3.61 billion tons of coal were consumed in China. Coal accounted for about $65.7 \%$ of China's primary energy in 2013 and is anticipated to remain the primary energy source well into the future. As more emphasis is placed on cleaner production and controlling air pollution, cleaner utilization of coal is a strong direction of future development. The use of briquettes instead of raw coal can reduce pollutant missions and

Y. Wang $\cdot$ X. Bai

Key State Laboratory for Coal Mining and Clean Utilization, Beijing 100013, China

Y. Wang $(\bowtie) \cdot X$. Bai $(\bowtie)$

Beijing Research Institute of Coal Chemistry, China Coal

Research Institute, Beijing 100013, China

e-mail: wangyue8211@sina.com

$\mathrm{X}$. Bai

e-mail: bxf1970@sina.com alleviate haze in coal combustion. For example, briquettes made of anthracite are recommended for heating in areas surrounding Beijing. Furthermore, applications of fixed-bed gasification technologies have increased rapidly, as have developments in coal-to-oil and coal-to-natural gas technologies. Briquetting is an effective way of supplying the gasification feedstock and improving economic efficiency.

Strength of the briquettes is the primary issue to be considered in briquette manufacture, but the intrinsic factors affecting the strength of briquettes have not been well researched, although relationships between structure and properties are the core of modern materials science. During assembling the components of materials, the macroscopic properties of the material are well known to be dominated by its microstructure (Olson 1997; Nan 2005). Research concerning relationships between the microstructure and the macroscopic properties is necessary to model and improve the performances of materials.

The performance of binders is crucial in the briquetting of pulverized coal using medium or low pressures (Xu and Liu 2001), especially for high quality coal. As important 
microstructural characteristics, the morphology and distribution of the binders have a strong effect on their performance. In this study, the microstructures (morphology and distribution) of binders in briquettes and their influence on briquette strength are discussed.

There are a variety of approaches for microstructure observation, which can be divided into direct and indirect observation methods (Xu 2011). Optical microscopy, stereo microscopy, and scanning electron microscopy are commonly used methods of direct observation, while nondestructive methods based on interferometry, acoustic emission, and $\mathrm{X}$-ray computed tomography are the main methods of indirect observation (Mehta and Monteiro 2006). Optical microscopy is widely used in quality assessment of raw materials and products, defect inspection, and design of new materials in the fields of rock mechanics, metallurgy, silicates (ceramics, cement), sintered minerals, composite materials, biology, and medicine. The morphology and distribution of binders in briquettes can also be characterized by optical microscopy. Binder microstructures can also be accurately measured by digital image-processing technology, which has seen rapid development and application in recent years. In this work, optical microscopy and digital processing technology were chosen to study the binder microstructures in the briquettes.

\section{Experimental}

A low-volatility bituminous coal from Changcun mine, Shanxi Province, was employed, and the compositional and chemical analyses of which are presented in Tables 1 and 2 . The coal was pulverized in a hammer crusher. The particle size distribution after crushing is given in Table 3 . Table 4 shows the analysis of the bentonite chosen as the binder for briquetting. Montmorillonite is the main mineral

Table 1 Compositional analysis of feed coal

\begin{tabular}{lll}
\hline & Air dried (\%) & Dried (\%) \\
\hline Moisture & 1.48 & \\
Ash & & 19.97 \\
Volatile & & 11.89 \\
Fixed carbon & & 68.14 \\
\hline
\end{tabular}

Table 2 Chemical analysis of feed coal

\begin{tabular}{lc}
\hline & Dry ash-free basis $(\%)$ \\
\hline Carbon & 90.37 \\
Hydrogen & 4.12 \\
Nitrogen & 3.53 \\
Sulfur & 1.53 \\
Oxygen & 0.45 \\
\hline
\end{tabular}

Table 3 Particle size distribution of feed coal

\begin{tabular}{lc}
\hline Size distribution $(\mathrm{mm})$ & Mass fraction $(\%)$ \\
\hline$>3$ & 1.5 \\
$2-3$ & 12.4 \\
$1.5-2$ & 10.7 \\
$1-1.5$ & 0.8 \\
$0.5-1$ & 24.5 \\
$<0.5$ & 50.1 \\
\hline
\end{tabular}

Table 4 Analysis of bentonite

\begin{tabular}{lr}
\hline Moisture (air dried, \%) & 6.28 \\
Ash (dry, \%) & 95.15 \\
$\mathrm{SiO}_{2}(\%)$ & 58.01 \\
$\mathrm{Al}_{2} \mathrm{O}_{3}(\%)$ & 14.34 \\
$\mathrm{~K}+\mathrm{Na}(\%)$ & 1.46 \\
Weight loss at high temperature (\%) & 10.54 \\
\hline
\end{tabular}

component of the bentonite (Jiang and Zhang 2005). As a common binder for briquetting, the bentonite is obvious in optical microscopy and can be easily distinguished from the pulverized coal particles and clay minerals in polished sections, which makes it a perfect binder for this study. The bentonite particle size was $<149 \mu \mathrm{m}$ (100 mesh).

\subsection{Preparation of the briquettes}

The briquetting mold was a cylinder of $40 \mathrm{~mm}$ diameter and $25 \mathrm{~mm}$ height. Briquetting was carried out using a MJTY (MSY)-58T hydraulic molding machine at a briquetting pressure of $12 \mathrm{MPa}$. Binder concentrations of $3 \%, 5 \%, 7 \%$, and $9 \%$ were studied. All constituents were measured in weight percent. The feed coal particles and the binders were stirred for $5 \mathrm{~min}$. After these components were fully mixed, water was introduced to give a briquette moisture content up to $12 \%$ (dry basis of feed coal). The coal/binder mixtures added into the mold were limited to $(30 \pm 0.2) \mathrm{g}$ to eliminate the influence of mass difference on the briquette strength (Richards 1990). The green briquettes were placed in an oven at $105{ }^{\circ} \mathrm{C}$ for $3 \mathrm{~h}$ to produce the product briquettes. Compressive strength (measured according to Chinese Standard MT/T 748-2007, 2007), impact strength (MT/T 925-2004, 2004b), and thermal stability (MT/T 924-2004, 2004a) were then determined for each group of briquettes.

\subsection{Observations of the binders in briquettes}

The observations of the binders were carried on polished sections of the briquettes, prepared using the boiling-rosin method for lump coal specimens, according to Chinese 
Standard GB/T 16773-2008 (2008). The numbers of specimens required to obtain representative values for quantitative analyses were selected according to Stach et al. (1982). Two polished sections were made for each group of briquettes. The longitudinal section of the briquettes was parallel with the compression direction during briquetting while the cross-section was vertical to the direction of compression.

Microstructural observations were conducted using a Zeiss ${ }^{\mathrm{TM}}$ Axioskop 40 polarizing microscope and images of the binders were taken using a CoolSnap ${ }^{\mathrm{TM}}$ microscopic digital camera. Quantitative determination of the binders was conducted according to Chinese Standard GB/T 8899-1998. The coordinates of the central point of each binder particle were recorded in a two-dimensional coordinate system established by ProScan ${ }^{\mathrm{TM}}$ software. The objective magnifications were 5 or 10 times and the eyepiece magnifications were 10 times. The binder particles were observed using $\times 10$ objectives. When the binder sizes were beyond the field of vision, a $\times 5$ objective was used. The morphological parameters, such as binder area, were determined by image processing software. Distribution diagrams were drawn using the coordinate values of the central points and the binder areas.

\section{Results and discussion}

\subsection{Morphology and distribution of binders}

Two forms of binders were found in the briquettes examined by optical microscopy. The binder was either agglomerated with the coal particles (Fig. 1a) or dispersed in the coal/binder matrix mixture (Fig. 1b). To enable bentonite to be used as the binder, grinding was required, which dramatically increased the surface area and electrified the particles. The charge force (Zeng et al. 2001) and surface tension (Liu et al. 2001) both contribute to agglomeration of the fine bentonite particles, some of which disperse in the matrix of the coal/binder mixture during the stirring and mixing steps of briquette preparation.

Small particles and dark colors were seen in the dispersed binders, which made quantitative analysis difficult, so this study focused on agglomerated binders. The binder addition was measured as the mass fraction per dry basis of the feed coal. The quantitative results from microscopic analysis are presented as units of volume fraction. The conversion of mass fraction to volume fraction is as follows:

$V=\frac{x / 2.68}{x / 2.68+100 / 1.46} \times 100 \%$

where $V$ is the volume fraction of binders $(\%) ; x$ is the binder concentration (mass fraction, \%).

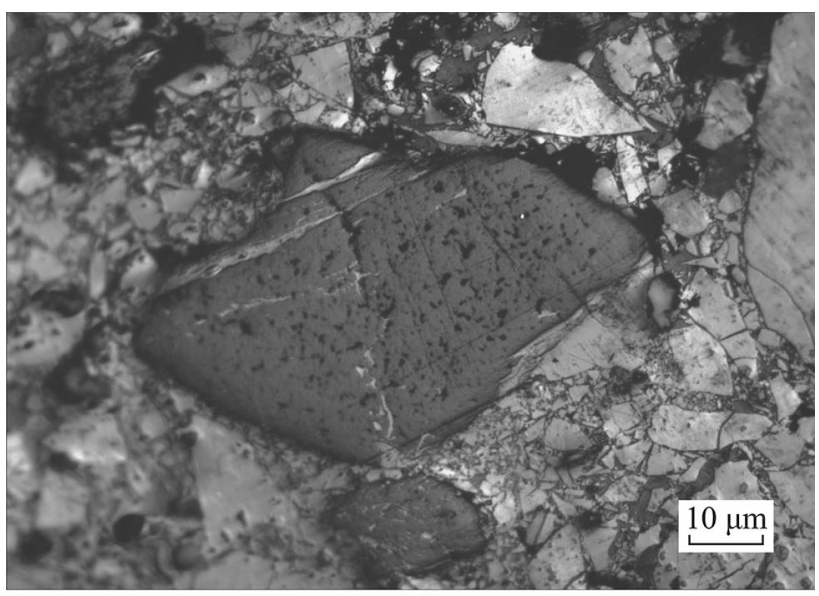

(a)

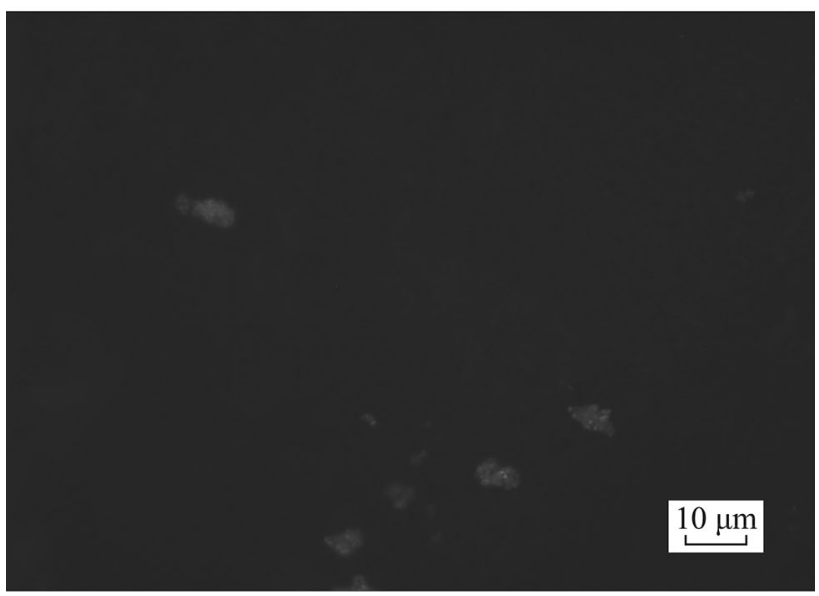

(b)

Fig. 1 Morphology of binders in briquettes. a Alomerated binder (reflected light, air, polarized light, $\times 100$ ). b Dispersed binder (reflected light, air, crossed polar, $\times 200$ )

Note: The true relative densities (TRD) of the bentonite and feed coal used in this study are 2.68 and 1.46, respectively.

True relative density was determined according to Chinese Standard GB/T 217-2008.

The volume fractions of detected binders are shown in Table 5. The volume determinations of briquettes made with $3 \%$ binder were based on the cross section. The binders in briquettes behave similarly to macerals in coal, so the test error for the binders followed the specifications of Chinese Standard GB/T 8899-1998.

As shown in Table 5, the observed binders accounted for about $50 \%$ of the total volume fraction, so the agglomerated binders are present in the briquettes in similar proportions to the dispersed binders. Friction between the binder and the polishing machine can cause some binder to fall off during preparation of the polished sections. Agglomerated binders fall out more easily than dispersed 
Table 5 Volume fraction of detected binders

\begin{tabular}{lllll}
\hline $\begin{array}{l}\text { Concentration } \\
\text { of binder }(\%)\end{array}$ & Section* & $\begin{array}{l}\text { Volume } \\
\text { fraction } \\
\text { calculated } \\
(\%)\end{array}$ & $\begin{array}{l}\text { Volume } \\
\text { fraction } \\
\text { observed } \\
(\%)\end{array}$ & $\begin{array}{l}\text { Observed } \\
\text { Calculated }\end{array}$ \\
\hline 3 & $\mathrm{C}$ & 1.60 & 0.845 & 52.8 \\
5 & $\mathrm{C}$ & 2.65 & 1.108 & 41.8 \\
& $\mathrm{~L}$ & & 1.335 & 50.4 \\
7 & $\mathrm{C}$ & 3.67 & 1.986 & 54.1 \\
& $\mathrm{~L}$ & & 1.796 & 48.9 \\
9 & $\mathrm{C}$ & 4.67 & 2.223 & 47.6 \\
& $\mathrm{~L}$ & & 2.082 & 44.6 \\
\hline
\end{tabular}

* $C$ cross-section, $L$ longitudinal section

binders. Greater amounts of the agglomerated binders fall out with amount increasing of binder added, which accounts for the decreasing proportion of observed binder as the additive increases.

Distribution diagrams of the binders in briquettes are shown in Fig. 2 (agglomerated binders are shown as circles with equivalent areas while dispersed binders are neglected). The aggregated binders with large differences in size are not well-distributed, which indicates an inhomogeneous briquette microstructure. Larger size differences are found for the agglomerated binders as the binder concentrations increase.

\subsection{Roundness of binders and its implications}

Spheroid or laminated structures (Yu and Liu 1989), which would be ellipses in two-dimensions, are used to represent the minor microstructural components. The concept of roundness is introduced to characterize the binder morphology in this study. Roundness is defined as the ratio of the long axis to the short axis for the equivalent ellipse of the binder particles. If this ratio is in unity, then the roundness of the binder particle is 1 . The roundness values of binders in different sections, made by using different quantities of binder, are shown in Fig. 3; the corresponding histogram is shown in Fig. 4.

As shown in Figs. 3 and 4, the binder roundness values are concentrated between 1.5 and 4.0, with a small fraction

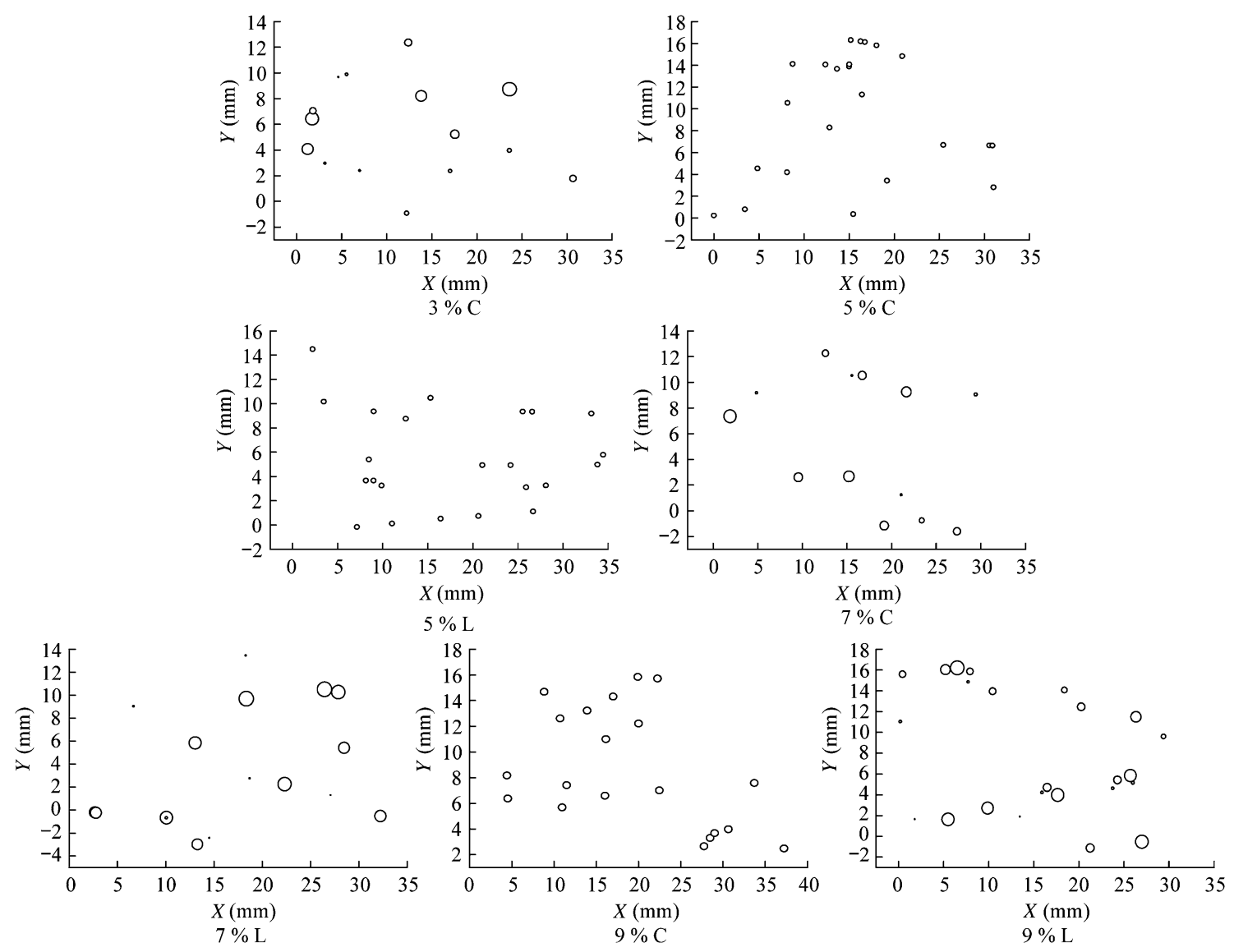

Fig. 2 Distribution diagrams of agglomerated binders in briquettes. The $X$ and $Y$ axes represent the two-dimensional coordinate system described in Sect. 2.2 


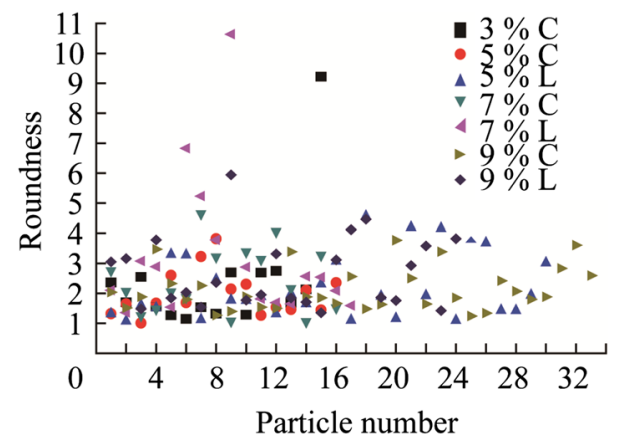

Fig. 3 Roundness of binders

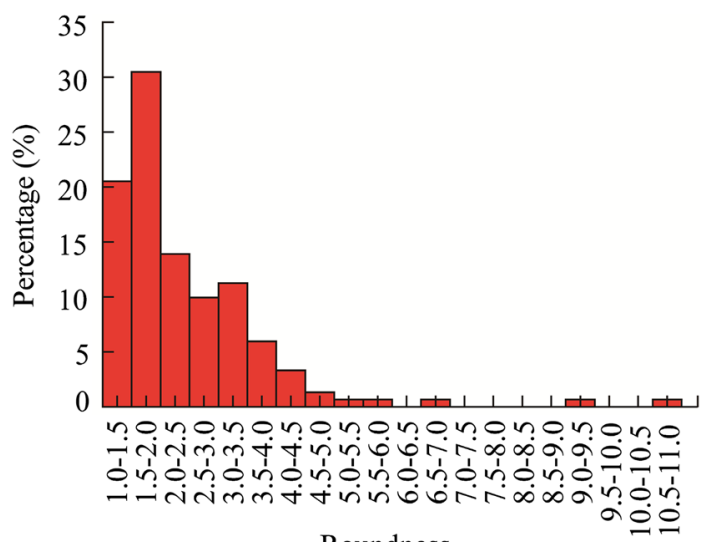

Fig. 4 Roundness histogram

close to 1 , and a few values above 4.0 in different sections of the briquettes with different binder concentrations. Bentonites in the longitudinal sections of briquettes with binder concentrations of $7 \%$ and $9 \%$ are more likely to have roundness values above 4.0. The roundness of bentonite free of compression is close to 1.0 , as shown in Fig. 5, which indicates that the roundness changing is caused by the pressure that the binders are subjected to during briquetting.

Most aggregated binders were compressed and conformed well to the surfaces of coal particles, with some binder particles changing shape when moving with the coal particles, thereby resulting in most binder roundness values between 1.5 and 4.0. Small quantities of the binders were subjected little pressure, so showed little change of morphology, and gave a roundness of approximate 1. The binders in the longitudinal section (compression section) of the briquettes with binder concentrations of $7 \%$ and $9 \%$ moved substantially and changed shape considerably, so these binders were more likely to have roundness values exceeding 4.0. Large-sized agglomerated binders, which experienced large morphology changes during compression, are found in briquettes comprising large amount of binders.

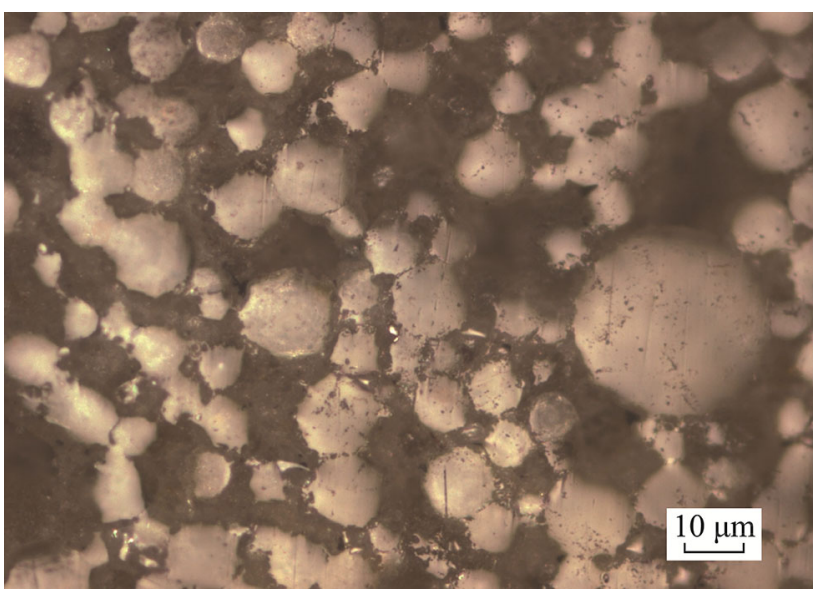

Fig. 5 Optical microscopy image of binders free of compression (reflected light, air, polarized light, $\times 100$ )

Table 6 Compressive strength, impact strength, and thermal stability of briquettes

\begin{tabular}{llllr}
\hline $\begin{array}{l}\text { Amount of } \\
\text { binder (\%) }\end{array}$ & $\begin{array}{l}\text { Compressive } \\
\text { strength (N/ball) }\end{array}$ & $\begin{array}{l}\text { Impact } \\
\text { strength (\%) }\end{array}$ & \multicolumn{2}{l}{$\begin{array}{l}\text { Thermal } \\
\text { stability (\%) }\end{array}$} \\
\cline { 3 - 5 } & & & $\mathrm{TS}_{+13}$ & $\mathrm{TS}_{-3}$ \\
\hline 3 & 105 & 27 & 75.1 & 16.9 \\
5 & 115 & 32 & 75.8 & 16.5 \\
7 & 202 & 48 & 84.5 & 10.7 \\
9 & 195 & 45 & 89.3 & 6.6 \\
\hline
\end{tabular}

$T S_{+13}$ the percentage of samples whose sizes were above $13 \mathrm{~mm}$ after the test, $T S_{-3}$ the percentage of samples whose sizes were under $3 \mathrm{~mm}$ after the test

\subsection{The influences of binder morphology and distribution on briquette strength}

The compressive strength, impact strength, and thermal stability of briquettes made with different binder concentrations are listed in Table 6. The relationships between briquette strength and binder concentration are shown in Fig. 6. Poor compressive strength and impact strength were found in briquettes with only small amounts of bentonite binder added.

The binders dispersed in the coal/binder matrix are believed to act as fully adhesive, which benefits the mechanical strength of the briquettes. The amounts of dispersed binders increased as the concentration of binder increased. Large, unevenly distributed, agglomerated particles of binders that shrank during the drying process can generate fractures in the spaces between the binders and the coal particles, which is harmful to the mechanical strength (Wang et al. 2013). A larger size difference was found for the agglomerated binders as the binder concentration 


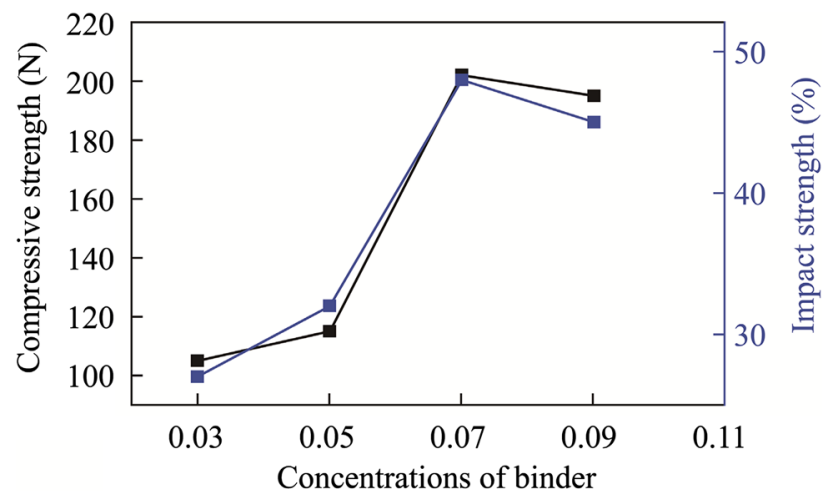

(a)

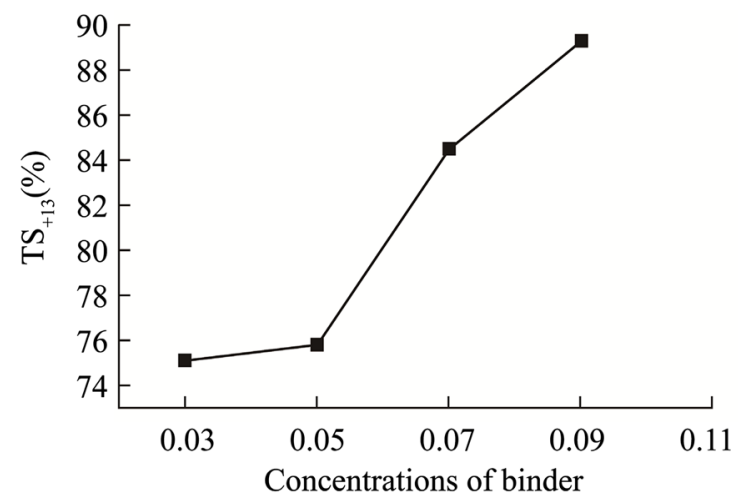

(b)

Fig. 6 Relationship between strength of briquettes and binder concentration. a Relationship between mechanical strength and concentrations of binder. b Relationship between thermal stability and concentrations of binder

increased. When small amounts of binder were used, the cohesiveness of the dispersed binders was the dominating factor, with small volumes of agglomerated binders in the briquettes, and so the mechanical strength of the briquettes increased as the binder concentration increased. When the binder concentration was high enough, the volumes of the agglomerated binders increased significantly and strengthcontrolling flaws were produced, so mechanical strength of the briquettes decreased as the binder concentration increased, as shown in Fig. 6a.

On the other hand, bentonites lose little mass at high temperatures, so large binder particles act as a "framework" in the briquettes, which is beneficial to their thermal stability (Xu and Liu 2001). Thermal stability increased with increasing binder concentration, as shown in Fig. 6 b.

Because of the conflicting influences on mechanical strength and thermal stability due to agglomerated binders, only a limited amount of binder can be used. The aggregated binder components were detrimental to briquetting overall.

Binders with roundness approximating 1 (little pressure in briquetting) acted as neither agglomerated nor dispersed binders, so these were "useless" in briquettes. Further study is needed to reduce the proportion of these types of binders. Binders with roundness above 4.0 were usually overloaded, so were not always beneficial and there was an upper limit on the amount of bentonite that can be used.

\section{Conclusions}

The morphology and distribution of binders in briquettes and their influence on briquette strength were studied by optical microscopy and digital image processing, which indicated:

(1) Aggregated and dispersed binders, which were present in similar proportions, are the major forms of binders in briquettes. Aggregated binders with large size differences are not well-distributed. Larger size differences are found for agglomerated binders as the binder concentration increases.

(2) The concept of roundness is introduced to characterize the binder morphology and indicate the pressure experienced by the binder during briquetting. This showed that most binders with roundness values between 1.5 and 4.0 were compressed and conformed well to the interfaces of coal particles, while those subjected to little pressure had a roundness approximating 1.0. The binders in the compression direction changed shape substantially.

(3) The morphology and distribution of the binders changed as the binder concentration increasing, thereby influencing the strength of the briquettes. Aggregated binders were detrimental to mechanical strength while dispersed binders benefited briquetting.

Aknowledgements The article was supported by the National Key Technology R\&D Program (2012BAA04B01) and the International S\&T Cooperation Program of China (2012DFR60360).

Open Access This article is distributed under the terms of the Creative Commons Attribution License which permits any use, distribution, and reproduction in any medium, provided the original author(s) and the source are credited.

\section{References}

GB/T 16773-2008 (2008). Method of preparing coal samples for coal petrographic analysis. Standards Press of China, Beijing

Jiang GL, Zhang PP (2005) Processing and application of bentonite. Chemical Industry Press, Beijing

Liu JJ, Zhou YP, Li SL (2001) Physical chemistry, 4th edn. Higher Education Press, Beijing

Mehta PK, Monteiro PM (2006) Concrete: microstructures, properties and materials, 3rd edn. McGraw-Hill, New York

MT/T 924-2004 (2004a). Determination of thermal stability of industrial briquette. China Coal Industry Publishing House, Beijing 
MT/T 925-2004 (2004b). Drop shatter test of industrial briquette. China Coal Industry Publishing House, Beijing

MT/T 748-2007 (2007). Determination of cold compressive strength of industrial briquette. China Coal Industry Publishing House, Beijing

Nan CW (2005) Physics of heterogeneous materials. Science Press, Beijing

Olson GB (1997) Computational design of hierarchically structural materials. Science 277:1237-1242

Richards SR (1990) Physical testing of fuel briquettes. Fuel Process Technol 25:89-100

Stach E, Mackowsky M, Techmüller M, Taylor GH, Chandra D, Techmüller R (1982) Stach's textbook of coal petrology (third edition). Gebrüder Borntraeger, Berlin
Wang Y, Bai XF, Wang DS et al (2013) Optical microscopic analysis of factors influencing cold strength of briquettes. Coal Convers 36(2):79-82

Xu SL (2011) Fracture mechanics of concrete. Science Press, Beijing Xu ZG, Liu SQ (2001) Briquetting technology. China Coal Industry Publishing House, Beijing

Yu NN, Liu GQ (1989) Stereology. Metallurgical Industry Press, Beijing

Zeng F, Hu YP, Yang Y, Ren SZ, Yang YF (2001) Particle technology of mineral processing. China University of Mining and Technology Press, Xuzhou 